\title{
LA PRÁCTICA DEL LIDERAZGO EN LA EMPRESA DE HOY. CÓMO EL LIDERAZGO PUEDE INCIDIR SOBRE LAS CONDICIONES DE SEGURIDAD Y LA EFICIENCIA DE LOS PROCESOS DE GESTIÓN ORGANIZACIONAL ${ }^{1}$
}

\section{THE PRACTICE OF LEADERSHIP IN TODAY'S BUSINESS. HOW LEADERSHIP CAN IMPACT ON THE SECURITY AND EFFICIENCY OF ORGANIZATIONAL MANAGEMENT PROCESSES}

\author{
Samuel Chávez Donoso \\ Asociación para la Prevención de Accidentes (APA), Chile
}

Palabras clave: empresa, liderazgo, resultados globales, empatía, reconocimento

Keywords: business, leadership, global results, empathy, recognition

Buenas tardes a todos.

Primero, quiero agradecer la presencia de cada uno de ustedes. $Y$ agradecer también la generosa presentación que me ha hecho Fernando Neira. El tema que pretendo compartir con ustedes, como ya se ha señalado, es: $L a$ Práctica del Liderazgo en la Empresa de Hoy.

Sobre liderazgo, yo no podría decir que soy un experto ni mucho menos, pero sí creo tener, por la edad probablemente y por el largo recorrido vital en la empresa, mucha experiencia; de hecho, creo haber cometido todos los errores posibles e imaginables en materia de liderazgo y si algunos se me ha escapado, que no deben ser muchos, les garantizo que fue involuntariamente.

Pero se dice que de los errores uno aprende; no es la mejor forma desde luego ni es un método que yo comparta, menos aun cuando se trata de conducir a un grupo de personas, a seres humanos, lo que es en realidad el liderazgo. $A$ veces uno comete muchos errores, muchas injusticias y cuando el tiempo va transcurriendo, uno va mirando hacia atrás y se da cuenta de que pudo haber hecho las cosas mucho mejor.

Por mi trabajo, he tenido la oportunidad de visitar y de conocer muchas empresas, muchos trabajadores, muchos supervisores, muchos ejecutivos y gerentes y de todos ellos he podido aprender. Algunas cosas tal vez muy recientemente; me habría gustado aprenderlas hace muchos años atrás, cuando empecé mi vida laboral. Recuerdo que cuando se me ofreció por primera vez ser supervisor, yo era muy joven y me sentí muy contento desde luego; me estaban dando la posibilidad de ser "jefe", cosa que un joven valora mucho. $Y$ recuerdo que le di las gracias muy sinceras a quien me ofreció esa posibilidad; le dije que era "un bonito desafío", que es una frase que uno la usa en estos casos especiales. Es un bonito desafío pero, cuando al lunes siguiente tuve que asumir ese cargo de dirigir a un grupo de personas, me di cuenta que no estaba preparado para ello. Me di cuenta que las tareas eran distintas, las funciones diferentes, las responsabilidades mayores y que yo ni nadie me había preparado para ejercer ese cargo, como debiera ser.

Entonces me prometí en aquella fecha que, cuando tuviera alguna experiencia acumulada, escribiría un libro; y tuve la oportunidad de hacerlo: El libro se llama SuperVisión dirigido obviamente a supervisores y luego, más recientemente, escribí otro libro asociado al liderazgo que se llama Hacia La Nueva Empresa.

Bueno, pero el título de la presentación es $L a$ Práctica del Liderazgo en la Empresa de Hoy. Eso ya da la idea de que hoy en día las cosas ya son diferentes: Todo ha venido cambiando, el mundo de hoy ya no es el mismo; nosotros hemos sido testigos privilegiados, de poder ver este proceso de globalización y de creación de este concepto de competitividad.

Si nos remontamos algunos años atrás, recordarán ustedes por lo que habrán leído, 
que el mundo era muy distinto. De hecho la Tierra era... iplana!; era plana para todos los que habitaban en este planeta; además, no se movía y lo más entretenido de todo es que éramos... "el centro del universo". A mí me hubiera gustado vivir en aquellos años, pero las cosas fueron cambiando y recuerdo que por ahí por los años 50 más o menos, un escritor y político latinoamericano, peruano, llamado Ciro Alegría, que por razones políticas fue deportado a Chile, estando allá escribió un libro que se llamó "El Mundo es Ancho y Ajeno". Esa era la visión que teníamos del mundo. Yo recuerdo que, siendo muy pequeño, escuchábamos esa frase con mucha frecuencia, porque graficaba muy bien cómo era el mundo en aquellos años: era un mundo inmenso, ancho, distante también; y ajeno porque lo que ocurría en cualquier otra parte del mundo no nos afectaba ni para bien ni para mal; es más ni nos enterábamos de las cosas que sucedían en otras latitudes.

Pero ese mundo ancho y ajeno de Ciro Alegría de pronto se nos achicó, con este proceso de la globalización que fue una verdadera explosión, en que el mundo dejó de ser ancho y dejó de ser ajeno y hoy todo está al alcance de la mano, el mercado es uno solo, uno puede ir con sus productos a cualquier parte del mundo, pero también todo el mundo puede venir con sus productos, donde estemos. Eso trae aparejado el concepto de competitividad y estando en un mundo pequeño, cercano y atrozmente competitivo a veces, en que los pronósticos aseguran, por lo menos así lo dice Jack Trout (uno de los pocos personajes que todavía se atreve a ser futurología), cuando señala que "va a llegar el momento en que todo el mundo intentará arrebatarle el negocio a todo el mundo". Ese es el vaticinio que hay, el pronóstico hacia dónde vamos con este tema de la competitividad, que a decir de algunos, la competitividad nos obliga a sacar lo mejor de las cosas pero también, desgraciadamente, a veces hace aflorar lo peor de las personas. Es algo a lo cual debiéramos estar atentos, porque no va a ser ese el mejor mundo, si es que nos vamos por ese lado.

El tema del liderazgo tiene incidencia también en aquello.

Pero así como ha cambiado el mundo, estamos en un mundo globalizado, pequeño, cercano, competitivo y lleno de cambios de todo tipo, implica que las empresas también tengan que ser diferentes para adecuarse a este nuevo mundo, en donde la velocidad es un factor importante para las empresas. Las empresas tienen que estar adecuándose constantemente $y$ aquellas que no adquieren un ritmo, una velocidad, dinamismo acorde a los tiempos actuales también empiezan a desaparecer y eso ha ocurrido con miles y miles de empresas en una especie de holocausto mundial. Empresas que desaparecen porque no han tenido la capacidad de adaptarse o de responder a este nuevo mundo, con la velocidad que se requiere.

Y así como han cambiado las empresas, también el trabajador de hoy es distinto. Cuando uno analiza los cambios producidos en el mundo, puede anotar mucho en el ámbito de las comunicaciones, en el ámbito de la tecnología y otros, pero también en aspectos sociales y humanos. Cuando uno recuerda cómo era la relación, hace unas pocas décadas atrás, entre padres e hijos, vemos que era distinta a la de hoy. Nuestra generación, cuando éramos jóvenes había, no sé si más respeto, aparentemente sí, pero había más disciplina u obediencia, había un mirar hacia arriba al padre, la figura paterna, había también algo de temor y castigo. Hoy día, esa relación ha cambiado, yo creo que para mejor; me parece más horizontal y más humana pero cuesta más ser padre hoy en día que antes.

Y así como ha cambiado la relación entre padre e hijo, de la misma manera ha cambiado la relación entre jefes y trabajadores. Recordando años atrás, la figura del jefe, del supervisor, del gerente era también de mucho respeto, también había disciplina y algo de temor. Bastaba lo que en algún momento se llamó la voz de mando para obtener obediencia, pero eso ya no existe. Hoy día, el trabajador de la empresa de hoy y en el mundo de hoy, también es diferente y lo que nos falta es aprender o adecuar los estilos de liderazgo a la realidad de hoy.

Ya no basta la voz de mando, el mundo ha cambiado, las empresas han debido adaptarse a los cambios. Lo que nos queda por cambiar, es a quienes tenemos la responsabilidad de dirigir a grupos de personas, para no seguir usando las formas, los métodos, los estilos, las técnicas de una época que ya se fue, que ya no existe y que no volverá. Eso nos invita a revisar lo que hemos hecho en materia de liderazgo, para poder rescatar aquello de valor que nos sigue sirviendo, pero también para desaprendernos de aquellas cosas que ya no sirven y para incorporar nuevas formas, nuevos estilos para el liderazgo. 
Entonces queremos hacer una breve descripción, en los minutos que tengamos, acerca del gerente y del supervisor de hoy, para el trabajador de hoy, en la empresa de hoy, en el mundo de hoy. Yo sé que esto es muy pretensioso, yo no soy una autoridad en esta materia como para decirlo, pero si para compartir con ustedes algunas ideas al respecto.

Los tiempos cambian, eso está claro, todo ha cambiado; es lo que por lo demás nos ha venido cantando Mercedes Sosa: "Cambia todo cambia"... ¿ ¿recuerdan? Hay también una chilena, muy querida para nosotros, Violeta Parra, que muchos de ustedes la ubicarán, que cantaba más o menos lo mismo, pero ella decía: "Cambia todo en este mundo ay ay ay". Pues, ¡ella agregó el ay ya ay! Como que ya se daba cuenta, sospechaba que los cambios iban a ser un poco dolorosos, como de hecho muchos lo son. Algunos cambios son para mejor, otros no tanto, pero hay que asumirlos.

Recuerdo que cuando comencé mi vida laboral como supervisor, la única responsabilidad que teníamos los supervisores en aquellos tiempos, era cumplir con las metas de Producción. Porque para la empresa lo único importante era producir; recordemos que en aquellos años los precios de los productos los fijaba la propia empresa: si una empresa producía un artículo a un costo de 100 y quería ganar 20, fijaba el precio en 120 y el mercado... ipagaba 120 ! Pero eso ya no fue más así, ahora los precios no los fija más la empresa, los precios los fija el mercado. Y si el mercado dice: mire señor, estamos dispuestos a pagarle 90 no más por lo que usted produce, las alternativas son: yo me adecúo a eso o chao como empresa; y eso es lo que ha pasado con miles y miles de empresas que no han sido capaces de producir lo que el mercado está dispuesto a pagar. Si la empresa está dispuesta a seguir funcionando, ganando 5 en vez de 20, igual tenía que ver cómo se las arreglaba para producir a 85 . Y si quería seguir ganando los 20, tendría que ver como producía a 70. Entonces ya no bastaba con tener solo metas de producción sino también a determinados costos, dentro de ciertos presupuestos, para poder hacer los productos vendibles. Y ahí adquiere más relevancia -estoy haciendo un poco de historia- el concepto de Productividad. Es importante la producción pero dentro de ciertos costos, que nos hagan poder competir con el mercado.
Después vino un momento que probablemente muchos recordemos, en que invadió con mucha fuerza el mundo el concepto de Calidad. Que desde siempre ha existido por supuesto, pero hubo un movimiento muy fuerte, hace unas pocas décadas atrás, en que alguien advirtió al mundo que la calidad iba a adquirir un valor supremo. Y la calidad pasó a transformarse en un concepto vital; y vital, en el sentido estricto de la palabra ya que está asociado a la vida de las empresas. Lo cual se puede sintetizar en la frase muy breve que dice: Sin calidad no hay clientes -eso está claro- y sin clientes no hay... ¿qué no hay? ¡Empresa! No hay empresa. Por lo tanto la Calidad es un aspecto vital para las empresas, si no estamos en condiciones de ofrecer al mercado productos de la calidad que el mercado pretende, quiere o acepta, no tenemos nada que hacer. Entonces las empresas tuvieron que preocuparse de cumplir ciertas metas de producción, dentro de ciertos costos, pero también garantizando la calidad que el mercado quiere.

$Y$ así se han venido sumando otros aspectos; vemos la Seguridad, que también siempre ha estado presente pero hoy en día es algo que la sociedad en general valora más y seguirá valorando mucho más. Así como las empresas o la sociedad hoy está preocupada, interesada por la famosa huella de carbono y con razón; ha venido generándose también un movimiento que creo yo será muy fuerte y que muy probablemente sea asociado a lo que se llamará la huella de sangre.

A la sociedad no solo le va a interesar conocer la cantidad de carbono emitido por las empresas sino que también con qué Seguridad estamos produciendo lo que queremos vender en el mercado. Las empresas entonces cada vez, le dan o deben dar más importancia a la producción, a los costos, a la seguridad, a la calidad, al medio ambiente, al clima laboral y es lo que hoy en día me he permitido englobar en lo que llamaremos Resultados Globales (RG).

\section{¿Qué es Resultado Global?}

\section{Resultado Global}

"Es TODO lo que resulta de la gestión de una empresa y/o de cada supervisor o gerente, dentro de su ámbito de competencia".

$Y$ hoy en día ningún supervisor, ningún jefe, ningún gerente asegurar que es un buen jefe 
o gerente por el simple hecho que cumple con las metas de producción, si no las logra a los costos debidos. Nadie puede asegurar que es un buen jefe o gerente porque cumple las metas de producción, dentro de ciertos presupuestos, si la calidad que está produciendo no es la que el mercado acepta. Nadie puede decir que es un buen jefe o gerente y sentirse muy orgulloso porque cumple las metas de producción, a bajo costo, con estándares de calidad adecuados a lo que requiere el mercado, si para lograrlo tiene algún par de amputados, gente lesionada, equipos dañados o casos fatales. Tampoco nadie puede decir que es un buen gerente, jefe o supervisor porque cumple las metas de producción a bajo costo, con productos de buena calidad, con buenos niveles de seguridad incluso, si para lograrlo contamina el medio ambiente o crea un clima laboral irrespirable.

El buen gerente, el buen supervisor de hoy, de la empresa de hoy, en el mundo de hoy, tiene que hacerse cargo y responder por lo que llamamos Resultados Globales. Y eso es: "todo lo que resulta de la gestión de cada uno de nosotros dentro de la empresa".

Algunos hasta se "espantan" con esto porque les parece demasiado, pero es porque nos hemos quedado un poco anclados en los paradigmas de antaño, donde lo único que importaba era la producción y nos ha costado salir de eso. A quienes les parece que eso es mucho, yo les diría que no es tan diferente o no es nada de diferente a lo que nos enseñaban nuestros padres cuando éramos nosotros muy pequeños, cuando nos decían desde chicos que "uno debía hacerse responsable de sus actos" ¿Lo recuerdan? ¡Esto es lo mismo! Cuando una empresa a uno lo nombra supervisor, jefe o gerente... y uno acepta, a partir de ese mismo instante uno se hace responsable de todo lo que resulta de sus actos, como supervisor, gerente o jefe. Es decir, de todo lo que resulta de su gestión.

Bueno, de ahí entonces que hoy en día deberíamos tener en claro cuál es la misión del nuevo gerente o del nuevo supervisor que, aunque resulte extraño, a mí por lo menos me llama mucho la atención, cuando en mis seminarios pregunto a los gerentes o a los supervisores ¿cuál es la misión que ellos tienen?; me llama la atención que no haya una respuesta instantánea, única y clara, siendo que es un pregunta clave, es ¡LA pregunta! En el fondo ¿cuál es la razón de ser, del gerente de hoy o del supervisor de hoy?; ¿para qué está?; ¿cuál es la gran tarea por la que tienen que responder? Después de pensarlo un poco, surgen algunas respuestas, todas son aparentemente correctas, pero todas son muy parciales y diversas, cuando deberían haber dado una respuesta única y, en mi opinión, la respuesta única debiera ser que la misión de gerente o del supervisor de hoy tiene que ver obviamente con re-sul-ta-dos. No es como algunos dicen, que la misión del gerente es planificar, es controlar, es facilitar, es motivar, es liderar o qué se yo. Todas esas respuestas son correctas, pero... ipara otra pregunta! Esos esos son medios. La Misión del supervisor o del gerente tiene que ver con resultados, porque las empresas se crean para obtener resultados. Compran equipos, maquinaria, herramientas, instalaciones ¿para qué?, para obtener resultados; contratan gente ¿para qué?, para obtener resultados; se organiza la empresa ¿para qué?, para obtener resultados. ¿Pero qué resultados? Resultados Globales.

Es en lo que debemos pensar ahora; no pensar sólo en resultados de producción, sino de producción, calidad, costos, seguridad, clima laboral, etc, que es hacia donde queremos focalizar el liderazgo. O sea, el liderazgo tiene sentido en la medida que lo ponemos orientado o en función de algo. ¿De qué en nuestro caso?: de cumplir con la Misión que tenemos que cumplir y eso no debiera ser otra que optimizar los Resultados Globales.

Eso lo mostramos gráficamente con esos cuatro cascos que pueden ver en el telón, donde el primero puede representar, por ejemplo, a la producción, es el casco de la producción; el mismo que los supervisores y los gerentes se ponen en la mañana todos los días y durante toda la jornada andan interesados, preocupados, a veces obsesivamente, por cumplir las metas de producción. Pero este otro segundo casco representa a la seguridad; éste no se usa todo el tiempo, desgraciadamente, al menos no en todas las empresas, ¿cuándo se usa más? cuando se celebra la semana de la seguridad o cuando hay una campaña de seguridad y ahí todos los gerentes y supervisores incluso dan charlas muy bonitas de seguridad, pero se terminó la campaña o se terminó la semana de la seguridad y dejamos de lado el casco de la seguridad y volvemos a ponernos el ya desgastado casco de la producción.

Lo mismo ocurre con este otro tercer casco que es el casco de la calidad; lo buscamos ur- 
gentemente cuando se aproxima una auditoría de calidad para certificar o para mantener una certificación; entonces empezamos a ordenar los papeles, los archivos, los registros, a veces a falsificar uno que otro dato también, para no perder la certificación. Y si logramos mantener la certificación, nos relajamos, quedamos tranquilos, guardamos o tiramos el casco de la calidad y de nuevo nos ponemos el casco de la producción.

Y lo mismo suele ocurrir con el caso del medio ambiente o de lo que sea.

Desde luego, esa no es la mejor forma, no es lo que deberíamos hacer. Lo que indica el sentido común, es que deberíamos mandar a fundir esos cuatro cascos en uno solo, que se podría llamar "El Gran Casco de la Gerencia/ Supervisión" y que tenga el sello de Resultados Globales. Y que cada día, desde el comienzo de la jornada hasta el final de ella, todos los que tienen gente a cargo y responsabilidad en la dirección de la empresa, trabajen en función de mejorar la Producción, los Costos, la Calidad, la Seguridad, el Medio Ambiente, el Clima Laboral, etc.: "Resultados Globales".

Esto que muestro ahora es un Modelo de Causalidad de Eventos Generadores de Pérdidas, sobre lo cual no vamos a profundizar por razones de tiempo. Pero si decir que no está construido sólo sobre las causas de accidentes, donde se habla de actos inseguros y condiciones inseguras. Aquí hablaremos de actos y condiciones incorrectas en el amplio sentido de la palabra. Cuando hablamos de eso, obviamente cuando hay actos y condiciones incorrectas que se apartan de los estándares o de las formas aceptadas como correctas, nos traen como consecuencia, diferentes problemas: de productividad, de calidad, de seguridad, de medio ambiente y otros, que generan lo que conocemos como derroches, defectos, daños y deterioros, a los cuales denominamos "El Factor 4D negativo".

El Factor 4D Negativo es una especie de gran virus que corroe la eficiencia de las empresas y que es el causante de un porcentaje muy cercano al $100 \%$ de las empresas que quiebran o desaparecen, por mucho que uno crea que la quiebra se debe a que las tasas de los créditos son muy altas o a cualquier otra explicación. En el fondo lo que hay detrás del fracaso de las empresas es el insuficiente control sobre las pérdidas que producen los derroches, los defectos, los daños y los deterioros, que son consecuencias o efectos de problemas de producción, calidad, seguridad y medio ambiente, respectivamente.

Estas causas directas, actos y condiciones incorrectas tienen causas básicas, llamadas también causas fundamentales, agrupadas en factores personales, factores técnicos y factores organizacionales, sobre lo cual hay ya bastante información. Pero eso a su vez tiene un origen, que es lo que Deming Ilama "la fuente de los problemas". Este modelo, como lo podemos ver en su parte superior, se ha ido configurando en base a las cinco preguntas ¿Por Qué? que algunos califican como "la fórmula Toyota para resolver problemas". Bueno, aquí también esta famosa fórmula nos invita a que cada vez que nos enfrentemos a algún problema de pérdidas, nos preguntemos cinco veces: ¿Por qué? ¿Por qué? ¿Por qué? ¿Por qué? y ¿Por qué?, para llegar a la raíz del problema, al origen del problema o, a lo que Deming llama la fuente de los problemas, que en el fondo son fallas omisiones o debilidades en los distintos sistemas y procesos de la empresa.

Quiero recordar aquí que Deming, gran personaje, que algunos le han denominado "el hombre que descubrió la calidad", una persona notable, que ha hecho un gran aporte al mundo en materia de calidad, exhortaba permanentemente a sus discípulos, diciéndoles: "Vayan a la fuente de los problemas, porque ellas son las verdaderas fuente de mejoramiento". Es decir, el consejo de Deming es: "no se dejen confundir por los síntomas de los problemas o por las consecuencias de los problemas, sino que vayan a la raíz, vayan al origen, vayan a la fuente de los problemas porque ahí están las principales y verdaderas fuentes de mejoramiento". Es un gran consejo, que coincide y se complementa por lo demás con el pensamiento de otro gran personaje, Russell Ackoff, un gran especialista en conflictos y problemas quien hace una distinción entre lo que llama resolver problemas y disolver problemas. Es muy importante, en el fondo él habla de resolver problemas, cuando uno los ataca o los aborda a nivel de causas directas, que son los síntomas de los problemas. Uno puede corregir ciertas deficiencias en los ambientes de trabajo, puede corregir algunos actos inseguros o algunos errores y todo va a seguir funcionando bien, pero por un tiempo muy breve; a los pocos días, a las pocas semanas va a volver a aparecer el mismo problema, porque solo lo hemos resuelto a nivel 
de síntomas. En cambio cuando nos vamos a la fuente de los problemas, ahí ellos se disuelven, por mucho más tiempo y capaz que para siempre, porque los hemos atacado en la raíz, en el origen, en la fuente.

Este modelo apunta a eso, a los tres niveles de causas y a los tres niveles de acción o de prevención. Hay un nivel básico de prevención cuando actuamos a nivel de las causas directas; un nivel medio de prevención, cuando actuamos a nivel de las causas fundamentales que es mucho mejor que atacar sólo los síntomas de los problemas; y hay un nivel de acción avanzado o un nivel de prevención avanzado, cuando somos capaces de identificar y corregir los sistemas o procesos involucrados.

También quiero hacer una breve mención a lo que ya anticipé, que le llamamos a esto las 4D, "el factor 4D negativo", cuyas pérdidas exceden en demasía lo que la mayoría de los gerentes cree e incluso de lo que están dispuestos a aceptar. Cuando hablamos de pérdidas no estamos hablando sólo de pérdidas económicas, sino que incluso de las pérdidas de vidas; cuando hay daños a personas en materia de seguridad, hay pérdida de bienestar, hay pérdidas de tranquilidad, en materia de calidad hay pérdidas de clientes y de mercado a propósito de los defectos y puede haber perdidas de imagen y pérdidas de distinta naturaleza y desde luego también pérdidas económicas.

Siempre que pregunto en los seminarios y en las empresas que ellas representan, si las pérdidas por derroche son nada, poco, muchas, o muy muchas, hay un poco de timidez en pronunciarse; pero la mayoría cree que no son tantas, que tampoco son nada pero no cree que son tantas. Sin embargo, hay estudios que indican que aproximadamente el $25 \%$ de las cosas que hacen las empresas son innecesarias: no contribuyen a ningún objetivo, no aportan a los resultados, no agregan valor a ningún proceso, para decirlo en términos más actuales. Un $25 \%$ de las cosas que hacen las empresas, y nosotros dentro de las empresas, no contribuyen a los resultados y eso es... iderroche!

Es un tema muy apasionante, porque no solo existe ese derroche sino hay también en toda empresa derroche de materiales, derroche de maquinarias, de energía en todas sus formas y en todo tipo de energía; derroche de ideas, que para mi gusto es el principal derroche que tenemos todavía en nuestras empresas. Hay también derroche de tiempo, de espacio, de cualquiera de los recursos que tenemos que administrar. Por lo tanto aquí hay un área de mejoramiento tremendamente importante para cualquier empresa.

Las pérdidas por defectos también son cuantiosas. Hay un gran personaje, uno de los grandes gurúes de la calidad, el señor Phillip Crosby, que es uno de los antiguos: de todos los grandes maestros de la calidad, es el único que sobrevive. Él fue asesor del proyecto espacial, de la década de los 60, 70 que puso al hombre en la luna, como recordamos. El es el inventor o creador del concepto "Cero Defecto", un sistema de calidad que fue muy popular en aquellos años. Él mantiene aún una gran organización en el estado de Florida en Estados Unidos y con su equipo ha llegado a determinar que el costo de los defectos es del orden del $20 \%$ de las ventas, para la industria manufacturera. Es una cifra que a mí me costó mucho creerla, aceptarla y primero entenderla. Hoy en día, los márgenes de ganancias de las empresas son de $3 \%$ o 4\%; $5 \%$ ya es fenomenal, ¿cómo puede perderse por defectos un $20 \%$ ? Me resistí mucho a pensar en ello, pero la respuesta no está, como uno piensa, en el costos de las cosas que se hacen mal y que se votan al tarro de la basura o que por último se re-procesan, porque eso representa un porcentaje muy ínfimo.

La verdadera magnitud de las pérdidas o de los costos de los defectos está en una frase que dije hace un poco rato: "Sin calidad no hay clientes y sin clientes no hay empresa". Cuando una empresa produce productos, sea un bien o un servicio defectuoso, va a empezar a perder clientes, va a empezar a perder mercado y como consecuencia de ello esa empresa puede desaparecer y estamos llegando al 100\% de las pérdidas. Pero también, así como uno pierde clientes y pierde mercado, también, por tener productos defectuosos, se le hace difícil conquistar nuevos clientes, nuevos mercados. $Y$ todo eso tiene costos de gran envergadura. La desaparición de muchas empresas se debe a que ellas no han sido capaces de entregar productos que al menos satisfagan a los clientes. Entonces las pérdidas sí, efectivamente, son cuantiosas.

Las pérdidas por daños, daño a las personas desde luego en primer lugar, pero también daños a equipos, a maquinaria, a herramientas, a instalaciones, paralizaciones, interrupciones de faena, etc; también son cuantiosísimas; y hay estudios internacionales que señalan que 
estas son del orden del 8 al 10\% del producto interno de cada país. Son cifras mayores.

Y las pérdidas por deterioros, aquí no hay mucha información agregada, pero hay ejemplos notables; en Chile por lo menos, hay empresas que han tenido pérdidas muy grandes a raíz de deterioro por impacto al medio ambiente.

Éste es entonces el factor $4 D$ negativo y hay mucho que hacer para mejorar o controlar las pérdidas debido a derroches, defectos, daños y deterioros. Y lo importante como mensaje para dejar acá en relación a este punto, es que: Estas pérdidas, debidas a derroches, defectos, daños y deterioros, que son cuantiosas, en realidad son... ¡Ganancias! Qué curioso ¿no? Si, son ganancias; pero son ganancias que la empresa está dejando de obtener. Y que en la medida en que las empresas tengan un sistema para controlar esas pérdidas, automáticamente se transforman en ganancias. Sin ningún trámite administrativo, sin ningún manejo contable, esto es automático, como la ley de vasos comunicantes, cada dólar o peso, que uno controle de derroche, automáticamente se manifiesta en el lado de las ganancias, así de simple y hay mucho que se puede hacer en esa materia.

Ahora, vamos a los Roles del supervisor.

Para que los supervisores puedan cumplir con su Misión, deben ejercer determinados roles. Los más comunes e importantes son: el rol de administrador de recursos, el rol de nexo dentro de la organización y el rol de líder de su grupo; o mejor, de su equipo. Pero estos roles se desempeñan y se cumplen en función de algo. ¿De qué?: de la misión del gerente o del supervisor, que tiene que ver como lo hemos señalado con ... Resultados Globales; al menos con producción, o productividad, calidad, seguridad, clima laboral y medio ambiente, cuyas pérdidas o las perdidas en cuyas áreas son de la magnitud que acabo de comentar.

Para entrar al tema, todo lo anterior era sólo para darle el sentido al liderazgo, digamos que:

\section{El liderazgo está o debe estar en función de los Resultados Globales que debemos obtener en nuestras respectivas organiza- ciones.}

Lo que vamos a comentar ahora no es que sean ni pretenden ser, desde luego, "LAS 7 claves". Nadie se puede atribuir el plantear cuáles son "las claves", ni mucho menos las 7 , las 8, las 4 ni las que sean. Estas que vamos a ver son algunas claves. Pero que para mí en lo personal son las "claves-clave", las más importantes de las claves. Como resultado, al menos, de lo que me ha tocado vivir, de la experiencia, de los errores que he cometido, de lo que he podido aprender de otros.

Cuando hablamos de liderazgo es bueno tener en cuenta que:

"El desempeño superior de las personas es, siempre, voluntario".

Sí. Ese desempeño superior no está en el sueldo, no está en el contrato. Ese desempeño superior hay que lograrlo, hay que conquistarlo; o, mejor aún, hay que merecerlo. Y eso es materia de motivación y es materia de liderazgo.

En todas las empresas existe lo que podríamos llamar un cierto nivel de desempeño aceptable o, más correctamente, un rango de desempeño, en que tanto la empresa como los trabajadores han llegado a acordar tácitamente y uno sabe que si se mantiene dentro de ese rango de desempeño no va a tener problemas y se va a poder llegar hasta jubilar en la empresa, si quiere. Pero si uno se desempeña por debajo de ese rango, corre el riesgo que lo despidan. Pero el desempeño superior, de ese rango hacia arriba, que no está en el contrato, que no está en el sueldo, ese desempeño superior es materia de liderazgo, 100\%: Hay que lograrlo, hay que conquistarlo, hay que merecerlo.

Recuerdo una famosa frase, ya muy antigua, del legendario Nikita Krushchov; algunos de ustedes se acordaran, otros no, que fue el primer ministro de la Unión Soviética, hace muchos años atrás, cuando la Unión Soviética era mucho más grande que la Rusia de hoy; era una organización mucho mayor y Nikita Krushchov era el Primer Ministro de la Unión Soviética, algo así como el gerente general de la empresa más grande del planeta: El estado soviético. Y un periodista occidental, una vez le preguntó a Nikita: ¿Cuántas personas trabajan para usted?, esperando que le diera una cifra de muchos millones de personas; pero Nikita se quedó pensando un rato y le dijo: "Aproximadamente la mitad".

Todavía andan muchas personas, cabizbajas y ya envejecidas por el mundo, preguntándose, ¿qué habrá querido decir este caballero? Pero la pregunta sigue vigente. Para los que tienen 10, 50 o 1000 personas a cargo, ¿cuántas trabajan realmente para usted?, ¿las 10, las 50 o las 1000 ?, ¿en un cien por ciento o aproximadamente la mitad?, ¿estamos obteniendo 
todo el aporte de las personas?, ¿estamos aprovechando plenamente sus conocimientos, sus capacidades, su experiencia, sus talentos, sus competencias, su iniciativa, su creatividad, en un cien por ciento o aproximadamente la mitad? Es un gran tema. Hay diversos estudios que señalan que un porcentaje muy alto de los trabajadores declaran que se mantienen en un nivel de desempeño ojala justo lo que se necesita para no perder el empleo y a veces un poquitito más para tener algún margen de seguridad. Porque el desempeño superior, hay que conquistarlo, hay que merecerlo y ahí hay un tremendo desafío para el liderazgo.

\section{Vamos a la Claves entonces.}

\section{La primera Clave: "Las Personas son Personas"}

Esta primera clave, tiene que ver con la visión que tenemos de las personas en el trabajo; tiene que ver con lo que llamamos el "Recurso Humano". En mis presentaciones, cuando pregunto qué o quiénes son el recurso humano, la respuesta es casi siempre la misma: las personas y yo pregunto: ¿todas las personas?, sí, todos. Algunos piensan que yo estoy tratando de hacer alguna distinción especial; o huelen a discriminación. Pero igual luego pregunto, ¿los supervisores también son recursos humanos?; también, me dicen ¿y el gerente general?, también, por supuesto, todos somos recursos humanos, me afirman unánimemente. $Y$ yo les digo enfáticamente: "No comparto esa idea". Para mí el gerente general de una empresa no es recurso humano. Los gerentes de área tampoco son recursos humanos; incluso los supervisores, hasta los de primera línea, tampoco son recursos humanos. Ahora -les digo- puede que algunos o muchos de ustedes no estén de acuerdo conmigo, pero yo simplemente planteo mi opinión; son cosas en las que creo: no afirmo que sea LA verdad obviamente, pero tengo algunos fundamentos y ojala si alguno o varios de ustedes cambia de opinión. Tanto mejor.

Ahora, los trabajadores, los trabajadores de nivel operativo, tam-po-co son recursos humanos. Nadie es recurso humano, ninguna persona es recurso humano, por algo muy sencillo: Las personas no somos recursos, sino algo muy distinto y superior a los recursos. Es más, dentro de una empresa, todo puede ser recurso, excepto nosotros las personas.
Ahora bien, ¿existe el recurso humano? sí, si existe, ¿son las personas el recurso humano? No, no son las personas. Entonces, ¿qué es el recurso humano?: El recurso humano son las capacidades de las personas, pero no las personas. El recurso humano, es el conocimiento de las personas, la experiencia de las personas, pero no las personas. El recurso humano son los talentos de las personas, sus competencias, pero no las personas. Por lo tanto, lo que debiéramos pretender administrar como recurso humano son las capacidades de las personas, pero no las personas. Las personas por lo demás no se administran, se lideran, es el tema que estamos tratando de introducir.

Esta distinción no es una distinción ni trivial ni meramente semántica, porque influye significativamente en los estilos de liderazgo y en el trato que le damos a nuestra gente. Es muy distinto un supervisor, un jefe o un gerente que en sus colaboradores ve a personas, que otro gerente, supervisor o jefe, que en sus colaboradores ve recursos, por mucho que le agreguemos lo de humano. Pero se nos ha incorporado en nuestra mente, la idea, el concepto de recurso humano $y$ todos hemos asumido que el recurso humano son las personas. Ahora, dado que ya existe el concepto y que está instalado, mantengámoslo, usémoslo, pero interpretémoslo como corresponde, es mucho más lógico y justo.

Hay otro concepto que también creo que debiéramos ya empezar a cuestionar y que se usa mucho en todas nuestras empresas, en todos nuestros países: El concepto de mano de obra. Si lo piensan bien, ¿han escuchado algo más reduccionista y peyorativo para referirse a una persona en el trabajo que mano de obra?, si al menos dijéramos cabeza de obra, sería un poquito más digno, porque le estaríamos reconociendo al trabajador la posibilidad de pensar, pero hablamos de mano de obra, y más aún, muchas veces buscamos mano de obra barata. $Y$ cuando escribimos en los formularios, en los registros en las empresas, en las columnas respectivas, ni siquiera ponemos mano de obra, ponemos M.O. hasta sin punto para que nos salga más económico.

Y, "curiosamente", mientras hablamos de mano de obra, no tenemos empacho en hablar, simultáneamente, de máquinas inteligentes, de equipos inteligentes, de semáforos inteligentes, de bancomáticos inteligentes. Casi todo es inteligente, excepto nuestra gente que es... mano de obra. Y después nos quejamos que 
cuesta motivar a la gente, que es difícil lograr el compromiso de la gente. Bueno, pero si las manos no se motivan, no se comprometen; los recursos no se motivan, no se comprometen.

Cuando nos re-sintonicemos y entendamos que "las personas en el trabajo siguen siendo personas" y que no se transforman ni en recursos ni en mano de obra, recién vamos a estar en condiciones de empezar las acciones de liderazgo que correspondan, pero mientras tanto, las posibilidades las veo muy escasas, muy tendiendo a cero. Tenemos que cambiar ese paradigma que nos ha hecho tanto daño y que debiéramos al menos re-interpretarlo.

\section{La segunda Clave: "Conozca a su Gente"}

Aquí les comento una anécdota: estaba una vez en un seminario de un grupo de supervisores de distintas empresas y en el primer recreo vi a un supervisor que empezó a conversar con otro, en forma muy animada, el otro supervisor lo escuchaba con muchas atención, empezaron a llegar 2, 3, 4, 5 supervisores más, al final había un grupito que me empezó a poner nervioso; yo me dije: capaz que están conspirando contra mí, que era el relator, entonces me acerque sigilosamente y no era eso, felizmente. Era que ese supervisor conversaba a los demás acerca de una maquina ultramoderna que había comprado recién su empresa y que estaba a su cargo. Era de una tecnología de punta, llena de cualidades técnicas y ese supervisor sabía todo acerca de la máquina, había hecho de verdad, varios cursos, había leído los manuales y los catálogos, al revés y al derecho y de verdad que impresionaba la cantidad de información y el manejo que tenia de los datos de ese equipo. Entonces cuando volvimos a la sala, dado el interés que había concitado, le pedí que pasara adelante y que nos contara todos acerca de ese equipo tan maravilloso. Él paso gustoso y dio una clase magistral, se lució ante todos los supervisores que eran de varias empresas y cuando llevaba ya varios minutos hablando sobre su equipo, con mucho entusiasmo, yo le dije: Oye, y ¿quién va a operar esa máquina que es tan cara? Fulano de tal me dijo y me dio un nombre. Y yo le dije: ¿Y cuánto tiempo lleva trabajando contigo Fulano de tal? Dijo, conmigo lleva 12 años pero en la empresa lleva algo más de 20 , es un operario con mucha experiencia y por eso le hemos asignado a él esa máquina. Bueno, le dije yo, ahora por favor hablamos de Fulano de tal: Caput !!! Aparte del nombre y del sobrenombre, no fue mucho más lo que pudo decir, o tartamudear. ¿Por qué? ¡Porque no sabía más! Yo creo que esa fue una gran lección: para él, para mí y para todos los que estábamos presentes. Es bueno que en las empresas conozcamos mucho de los equipos, de la maquinaria, de la tecnología, de los procesos, de la competencia, de las estrategias, de todo, pero no es bueno que releguemos a nuestra gente a un plano secundario o más abajo aún. Una de las grandes falencias y deudas que tenemos, es conocer a nuestra gente en su dimensión humana. Es imposible liderar a un grupo de personas si no nos interesamos en conocer a la gente. Nadie puede administrar bien las cosas que no conoce bien y con mayor razón no podemos liderar a las personas si no las conocemos como personas, más que como meros de instrumentos productivos.

\section{La tercera Clave: "Aprenda a Escuchar"}

Un tercer aspecto clave es saber escuchar. Hoy día se reconoce al saber escuchar como la principal cualidad o virtud de un líder. Esto a mí me impactó hace muchos años, cuando leí una entrevista a un ejecutivo chileno que era el señor David Turner, que era presidente de la Shell en Chile y lo curioso era que este caballero había comenzado a los 18 años de edad en la misma empresa, pero como mensajero. O sea, partió en el puesto más modesto y llegó a la cumbre en una gran compañía. Entonces la pregunta de la periodista era obvia, le dice: usted señor Turner que ha tenido una carrera tan exitosa, ¿cuál cree usted que es la principal virtud de un líder? y él dijo: "saber escuchar", y agregaba lo siguiente, decía: Cuando era joven hablaba mucho y escuchaba poco, hoy día hago todo lo contrario y me va mejor.

A mí me descolocó esa respuesta, porque yo pensaba en aquellos años, que la principal cualidad de un líder era ser bueno para hablar; el que era capaz y que tenía el coraje de parase frente a un grupo y hablar, uno decía, "ese tiene pasta de líder". Este hombre decía: no, la principal virtud de un líder es saber escuchar y eso es así, hoy más que nunca. El autor más prolífico en materia de liderazgo, que es el señor John Maxwell, que ha vendido algo así como dieciocho millones de libros sobre liderazgo, en todos sus libros reserva un capitulo o algo para destacar que la principal cualidad de un líder, hoy, es saber escuchar. 
Cuando uno analiza o estudia un poco el tema, también se encuentra con que hay investigaciones, de hecho yo me encontré a poco de haber leído esa entrevista, con una investigación hecha en una universidad norteamericana, donde se buscaba encontrar las 20 cualidades más importantes de un líder. Y las clasificaron en 3 grupos: a las primeras 4 le llamaron súper críticas, a las 6 siguientes altamente críticas y a las 10 restantes simplemente críticas; también importantes porque estaban dentro de las 20. Pero la más importante de las súper críticas era escuchar activamente; así que parece -me dije yo- que el señor Turner tiene razón.

Cuando uno lee las biografías de los grandes vendedores del mundo, ve que todos coinciden en que la principal cualidad de un buen vendedor es la capacidad de escuchar. Hay un señor, que se llama Ben Feldman, que fue catalogado durante 4 años consecutivos como el vendedor más grande de los Estados Unidos y probablemente del mundo; si era de Estados Unidos capaz que también lo fuera del mundo. Cuando se conversa con él acerca del tema dice: "mi oído es un tesoro, yo cuando voy a hacer un negocio con algún cliente -dice- hago muy pocas preguntas al principio, no hablo más de un par de minutos para hacer las preguntas que preciso y después me limito a escuchar, a escuchar, a escuchar, a escuchar $y$ al final sé exactamente lo que tengo que decir para materializar la venta". Porque mientras escuchaba las respuestas a las preguntas que él inteligentemente hacía, conocía cuáles eran los problemas de la gente, las necesidades, sus gustos, sus posibilidades, sus preferencias, todo; por lo tanto la venta se hacía muy fácilmente.

Para liderar es lo mismo, no podemos motivar a la gente si no las conocemos, si no sabemos cuáles son sus problemas, sus necesidades, sus aspiraciones, etc. y para conocer a la gente hay que darse el tiempo de escuchar y escuchar con todo. Hoy en día hemos aprendido que uno no solo escucha con los oídos, también escucha con los ojos y con todos los sentidos. $Y$ también hay que aprender a escuchar con el corazón.

Esto que puede sonar un poco extraño, no lo es tanto, cuando analizamos los dos actos básicos de la comunicación que son: el hablar y el escuchar. Cuando nos centramos en el hablar todos estamos conscientes que uno no solo habla o se expresa con la boca, todos sabemos que uno se expresa con los gestos, con la actitud, con la palabra, con todo el cuerpo y también cuántas veces no hemos dicho: "Fulano de tal nos habló con el corazón". Y claro, porque para transmitir afectos, para transmitir sentimientos o emociones no basta con el acto mecánico de una boca que se mueve; las emociones, los afectos, los sentimientos se generan, nacen y se transmiten desde el corazón. Si eso es así para el hablar... ¿por qué no debe ser lo mismo para el escuchar? Podemos escuchar también con los ojos y con todos los sentidos, pero también podemos y debemos escuchar con el corazón. Para que haya una comunicación de cabeza a cabeza, en el plano racional, intelectual, pero también de corazón a corazón; una comunicación en el plano afectivo, que es necesaria para el liderazgo.

\section{La cuarta Clave: "Practique la Empatía"}

La empatía es un concepto muy importante y de mucho valor. Todos ustedes saben, me imagino, qué es la empatía. Me gustaría que me dieran todos, una respuesta al unísono: ¿Qué es la empatía? "la capacidad de ponerse en el lugar del otro". Bien, pero quiero decirles que yo no estoy de acuerdo con esa definición. Si eso es empatía, quiere decir que la empatía no existe, porque nunca nadie se va a poder poner en el lugar del otro y no estamos hablando físicamente, desde luego, todos sabemos de qué se trata. Pero si a un amigo mío, muy querido, se le muriera un ser muy cercano, con quien él se crió y pasó una vida de mucho agrado y tiene muchos recuerdos y yo quiero ser empático con él, yo jamás me voy a poder poner en el lugar del él. A quien se le murió su ser querido fue a él, él vivió con esa persona muchos años, lo crió, lo malcrió, etc., por lo tanto la empatía definida como algo así de que "es ponerse en el lugar del otro" y que algunos lo grafican más todavía diciendo que es ponerse en los zapatos del otro, ojala fuera así.

Yo sé que es figurativo, pero la idea que prevalece es que la empatía es ponerse en el lugar del otro. Si eso es empatía, para mi gusto la empatía no existe; por lo tanto, me he atrevido a modificar un poco el concepto de empatía, diciendo que: "La empatía es la actitud, la disposición, la capacidad y el esfuerzo necesario de hacer, consciente y deliberadamente, para aproximarnos lo más posible a la posición de algún otro". No es algo instantáneo, implica una actitud, una disposición, un esfuerzo deliberado 
y consciente para acercarnos lo más posible, pero nunca vamos a llevar al lugar del otro".

La empatía forma parte de una familia de varias palabras, en que la primera es la antipatía; todos sabemos que la antipatía genera rechazo. Más arriba de la antipatía, que genera rechazo, está la apatía que produce indiferencia; un poco más arriba está la simpatía, que facilita la aceptación y más arriba todavía como un valor supremo está la empatía, que es para comprender a los demás, para comprender al prójimo, para comprender a otro ser humano; no es para justificar nada ni a nadie, es simplemente para com-pren-der. Para comprender por qué una persona piensa como piensa, por qué dice lo que dice, por qué actúa como actúa; en definitiva, por qué esa otra persona es como es. No es, repito, para justificar nada ni a nadie, es para comprender y a partir de ahí poder hacer lo necesario para que la persona cambie si es eso lo que queremos.

Recuerdo un programa de televisión hace un par de años en Chile que se trasmitía desde las cárceles, estuvieron muy de moda. Partió un canal después se sumó otro y luego y otro y al final casi todos los canales transmitían programas desde las cárceles. Y había un programa donde había un preso, un joven que estaba preso por violación, tráfico de drogas, robo con intimidación y no sé qué cosas más; era como le llaman ustedes aquí en Uruguay: "completito". Y respondía muy bien a las preguntas del periodista, un periodista muy avezado que de repente lo empieza a acorralar con preguntas (al preso). A mí me llamaba la atención que respondiese tan bien, pero en un momento se sintió muy acorralado...y, para zafarse de ahí, el preso le dijo al periodista: "Mire, si yo hubiese sido hijo de sus papás, a lo mejor sería yo quien estuviera haciendo esta entrevista"... ¡Eso es empatía! Quise entender yo también, aunque el preso no lo dijo, que si el periodista hubiera sido hijo de los papás del preso, que a lo mejor también eran borrachos, narcotraficantes, violadores y todo; si hubiera nacido en el ambiente donde el nació, en la casa que nació, en el barrio que vivió, con los amigos que tuvo que a lo mejor también eran iguales. Si hubiera ido al colegio que fue, o que a lo mejor ni siquiera fue, probablemente sería el periodista quien estaría ahí en la cárcel. La empatía es... para comprender.

Sólo recién vamos a estar en mejores condiciones para comunicarnos mejor, para motivar a otra persona para que cambie. La empatía es un aspecto fundamental para la comunicación, para la motivación y para el liderazgo en general.

Vamos ahora a la Clave número cinco: "¡Use el Poder del Reconocimiento!"

El tema de la motivación, lo sabemos todos, es un tremendo tema, un temazo. Se ha escrito mucho sobre eso, pero para mí, si hay una palabra clave, casi mágica para la motivación, es la palabra reconocimiento.

Recuerdo que una vez en una conferencia de un gran personaje, habíamos más de doscientas personas hace muchos años atrás; era un conferencista que era un gigantón, con un vozarrón increible, siempre que se paraba ante un grupo se imponía por presencia y además las cosas que decía eran muy sabias y estaba dando una clase magistral acerca de la motivación en el mundo del trabajo. De repente detiene su presentación y dice: "Quiero hacerles una pregunta..." "quiero que levanten la mano quienes de ustedes durante el último mes han recibido alguna felicitación o reconocimiento de parte de su jefe". ¿Qué creen ustedes que pasó?: Ninguno levantó la mano; al principio hubo un silencio, de pronto brotaron algunas risitas sarcásticas que empezaron a cundir por la sala. Pero ninguna mano se alzó.

Alguien, recuerdo que pidió la palabra para decir "bueno a lo mejor nuestros jefes creen que para eso se nos paga y que con nuestro deber no más cumplimos". Fueron las únicas defensas a nuestros jefes. Pero en general, la impresión que reinaba en la sala era que nuestros jefes eran unos canallas; o al menos unos personajes fríos e indiferentes a nuestros esfuerzos por hacer las cosas bien. Pero Frank, que así se llamaba el conferencista, sabia o esperaba esa respuesta, seguramente; $y$, para poner el dedo en la llaga vuelve a preguntar " ¿Es que no han hecho nada bueno el último mes, ustedes?". Bueno, Frank siguió con su conferencia tan magistral como venía y al cabo de unos quince o veinte minutos después dice: "tengo otra pregunta" "¿Quiénes de ustedes, en los dos últimos meses, han ido al taller, a la planta, con el propósito deliberado de encontrar algo bueno por lo cual felicitar a algún trabajador?" La primera parte de la respuesta fue la misma: silencio, pero ya no hubo risitas sarcásticas; la mayoría bajaron o bajamos la cabeza, haciéndonos los tontos, como que tomábamos nota 
en el bloc de apuntes, pero ninguna mano se levantó. Conclusión: Nosotros también éramos unos canallas, o personajes fríos e indiferentes a los esfuerzos de nuestra gente por hacer las cosas bien.

Somos mezquinos para el reconocimiento, somos tacaños para la felicitación y cicateros para el agradecimiento. Estamos mucho más concentrados en los defectos, en los errores, en las cosas malas, para hacerlas notar y poco orientados a ver las cosas buenas y ponerlas de relieve, cuando al menos deberíamos lograr un equilibrio en la balanza motivacional, entre desalentar lo incorrecto y alentar lo correcto. Sobre todo cuando, creo que todos estamos de acuerdo, Wilcox nos recuerda que: "Una palmadita en la espalda dista sólo dieciocho pulgadas y media de una patada en el trasero, pero hay muchas millas de distancia en los efectos, en los resultados". Y, sin embargo, no lo usamos.

Todos los que hemos recibido algún reconocimiento alguna vez, sabemos lo que se siente: el pecho como que se hincha, el corazón late un poquito más rápido; es una sensación que no se olvida con los años. En mis seminarios y talleres a supervisores, normalmente comienzo preguntando cuál es la satisfacción más grande que han tenido en su vida laboral y muchos de ellos mencionan algún reconocimiento hasta de hace quince o veinte años atrás, cosas que duran, y sin embargo no usamos. Lo que podemos llamar hoy en día "el enorme poder del reconocimiento". Un reconocimiento sí, que sea merecido, que sea oportuno y que sea sincero. Si se cumplen estos tres requisitos, el reconocimiento va a entregar efectos importantes.

Hace no mucho tiempo atrás, un grupo de amigos invitamos a un gerente de una empresa que destacaba a nivel nacional como una empresa que tenía el mejor clima laboral; quisimos conversar con él y para ello lo invitamos a una cena (que había que financiarla entre todos lo que éramos los que invitábamos) y después de las palabras preliminares cuando empieza a hablar dice: "Miren, yo creo que lo mejor que pueden hacer la mayoría de las empresas y gerentes, en relación a la motivación, es... Y Ahí estábamos todos con los ojos abiertos esperando. Y él dice: "nada". Nos miramos entre todos, desconcertados y recordando que debíamos pagar la cena por ese extraño consejo. Pero cuando empieza a explicar, le encontramos la razón: ¿Cómo es la motivación de un trabajador nuevo cuando recién llega a una empresa? ¿Baja, mediana o alta? ¡Alta pues!; lo único que quiere un trabajador nuevo es hacer las cosas bien, simpatizarle a todo el mundo, llevarse bien con el jefe, hacer carrera ojala, dentro de la empresa. Pero ¿Qué es lo que pasa con el tiempo con esa motivación alta?, empieza a decaer, y ¿qué es lo que la hace decaer?: es la empresa, son los sistemas de trabajo, los estilos de liderazgo, es el trato que le damos a nuestra gente, lo que hace que esa motivación inicial que era alta, baje.

Lo que decía este gerente es que no hay que hacer nada, porque lo que hacemos, hace que la gente se desmotive. Si recibiéramos gente nueva desmotivada el tema seria cómo motivar a la gente, pero el punto es al revés: la preocupación debiera ser cómo logramos que ese trabajador no se desmotive. Reconocimiento, es la palabra clave.

\section{Clave número seis: "Ejerza un Liderazgo Visible".}

Aquí, para esta clave número seis, se exhibe el video "Liderazgo Visible", que los interesados pueden acceder a él en el canal de youtube Rekrea online, o en la página www.rekrea.cl

Bueno, y como hemos anunciado siete Claves, la última es: "Sea Persistente".

Todo lo que hemos conversado requiere, obviamente, de voluntad; y sobre todo también de persistencia, para seguir avanzando en esta línea de liderazgo, que es por lo menos la que visualizamos y queremos proponerles.

La persistencia es uno de los valores importantes, es gracias a lo cual la humanidad muestra logros, inventos, progresos, desarrollos; porque ha habido gente muy persistente en el avance científico, tecnológico, en la medicina, en todas partes. Thomas Alva Edison probablemente sea el paradigma de la persistencia; dicen que logró inventar la ampolleta después de diez mil experimentos; sus amigos más cercanos en broma le decían: "Sí, pero cometiste nueve mil novecientos noventa y nueve errores". Y él respondía tranquilamente: "No, no cometí ninguno; descubrí nueve mil novecientas noventa y nueve formas de cómo no hay que hacerlo". Ya estaba en su bagaje de conocimiento, cualquier otro que quisiera inventar la ampolleta tenía que atravesar por todo eso. Él ya lo había hecho. 
A propósito de persistencia, leí hace no mucho en un diario, un diario chino, una noticia que venía de Taiwán, de Taipei. El titulo decía algo así como "Un Ejemplo de Persistencia", me llamó la atención, quise leerlo y la noticia decía que un joven le escribió más de setecientas cartas a una muchacha declarándole su profundo sentimiento de amor y la nota decía que esta inusual muestra de persistencia, de escribir una carta cada día durante dos años, había terminado finalmente con que la muchacha había contraído matrimonio... pero con el cartero; quien la contactó setecientas veces en forma personal al ir a dejarle dichas cartas. Moraleja: Hay que ser persistentes, pero hay que darse cuenta que hay cosas que no se pueden delegar. El liderazgo es algo que no se puede delegar; hay que hacerlo en forma personal.

El liderazgo debe tener su "Para Qué", su razón de ser, y eso como vimos al principio, tiene que ver con resultados. El liderazgo es, no para pasarlo bien solamente, sino que es para trabajar de la mejor forma pero en pos de los resultados que vamos a obtener. ¿Qué resultados?: en nuestra opinión al menos, Resultados Globales, que es, por lo demás, la Misión del supervisor y del gerente de hoy, para la empresa de hoy, en el mundo de hoy.

Muchas gracias a todos ustedes.

Para citar este artículo:

Chávez, S. (2013). La práctica del liderazgo en la empresa de hoy. Cómo el liderazgo puede incidir sobre las condiciones de seguridad y la eficiencia de los procesos de gestión organizacional. Ciencias Psicológicas VII (1): 69 - 81.

1 (N. de la Ed.) Conferencia dictada por el Ing. Samuel Chávez Donoso el 22 de octubre de 2012 en el marco de las actividades de los programas del Postgrado de Psicología del Trabajo y las Organizaciones (revisado por el autor). Profesor invitado por el Departamento de Psicología Social y Organizacional de la Facultad de Psicología de la Universidad Católica del Uruguay.

El Ing. Samuel Chávez Donoso, es Director General de la APA Chile.

Ingeniero con un MBA en Dirección General de Empresas de la Escuela de Negocios Española IEDE. Ha escrito numerosos artículos sobre gestión de la prevención, control de pérdidas, liderazgo y supervisión, algunos de los cuales han sido publicados en España y en diversos países latinoamericanos. Es autor de ocho libros entre los que se destacan: "Re-Pensando la Seguridad como una Ventaja Competitiva", "Re-Emplazando Paradigmas", "SuperVisión" y "La Nueva Empresa". Conferencista invitado en Argentina, Bolivia, Colombia, Costa Rica, Chile, Ecuador, Estados Unidos, Perú y Uruguay.

Ha sido el creador del concepto "Procalsedad", un enfoque sistémico que integra Productividad, Calidad y Seguridad. Y, más recientemente, como consecuencia evolutiva, ha acuñado el concepto de "Resultados Globales, RG".

En 1996, el Consejo Nacional de Seguridad de Chile, le distinguió como "El profesional de Prevención - 1995", por el aporte que ha hecho al desarrollo conceptual de la profesión. En el 2007 le fue otorgada la Distinción ALASEHT 2006, en la categoría "Persona Natural", por parte de la Asociación Latinoamericana de Seguridad e Higiene en el Trabajo. 